\title{
Ratcheting effect of reinforced graphite sheet with stainless steel insert (RGSWSSI) under cyclic compression at elevated temperature
}

\author{
X.T. Zheng ${ }^{1}$, W.C. Dai ${ }^{1}$, H.F. Chen ${ }^{2} *$ J. Shen $^{3}$
}

1. Hubei Provincial Key Laboratory of Chemical Equipment Intensification and Intrinsic Safety, Wuhan Institute of Technology, Wuhan 430205, P. R. China

2. Department of Mechanical \& Aerospace Engineering, University of Strathclyde, Glasgow G1 1XJ, UK

3. School of Aerospace Engineering, Tsinghua University, Beijing 100084, P. R.China

${ }^{1}$ Author to whom correspondence should be addressed;

Electronic mail: haofeng.chen@strath.ac.uk 
Abstract : Ratcheting and creep of RGSWSSI are tested under cyclic stress-controlled compression by a self-designed clamp from $500^{\circ} \mathrm{C}$ to $600^{\circ} \mathrm{C}$. The effects of insert type, temperature, stress amplitude, stress rate, creep and loading sequence are considered. Results present that ratcheting deformations for RGSWSSI with 316L stainless steel tanged and bonded insert approach to each other and show little rate-dependence, while they slightly increase with the increment of stress amplitude and temperature. Moreover, obvious ratcheting effect takes place under cyclic pulsating loads with the peak stress of $32 \mathrm{MPa}$ at $500^{\circ} \mathrm{C}$ or higher. The accumulated deformations of RGSWSSI under small stress amplitude only increase during about the first 25 cycles, and then always turn to shakedown. It can also be estimated by the corresponding static creep strain in practical engineering with good accuracy at high temperature. This work provides important data and understanding of RGSWSSI under harsh fluctuating loads.

Keywords: Reinforced graphite sheet; Cyclic compression; Ratcheting; Creep; Elevated Temperature 


\section{Introduction}

Flat graphite sheets reinforced with stainless steel tanged insert or bonded insert have been widely applied in nuclear, chemical, petrochemical, and other industries as gaskets to ensure the sealing or tightness of key components, such as pumps, valves, flange joints and so on, due to their excellent compression resilience, sealing performance, chemical resistance between a wide operating temperature range. Noting that the stainless steel tanged insert is a thin stainless steel sheet with small serrated sieve pores made by punching process, as shown in Fig.1. The flexible graphite sheet, which is composed of multilayered flexible thin films made by compacting expanded graphite powder ${ }^{[1]}$, is the key element for the sealing performance, chemical resistance and compression resilience behavior of RGSWSSI, while those stainless steel tanged inserts or bonded inserts are essential for its strength and rigidity. Under practical operating conditions, gaskets are usually subjected to repeated compressive loads with small or great stress amplitudes due to the randomness of vibrations, pressure or temperature fluctuations, start-up or shut-down processes and so on ${ }^{[2]}$. In these cases, the accumulated deformation of RGSWSSI usually occurs, which is essential to evaluate the sealing performance of joints, especially at elevated temperatures ${ }^{[3,4,5]}$.

Metallic and non-metallic materials under repeated non-elastic tension and compression usually produce accumulated deformations, which enhance gradually with the increasing of number of cycles, namely the ratcheting effect. Many researchers studied ratcheting features of metal materials considering temperature-dependency ${ }^{[6,7]}$, time-dependency $\left.{ }^{[8}, 9\right]$, multiaxiality ${ }^{[10,11]}$, anelastic effect $^{[12,13]}$, cyclic softening ${ }^{[14]}$, and mean stress ${ }^{[15]}$ etc. The ratcheting effect is an key index to assess the shakedown behavior of eigineering structures ${ }^{[16,17,18,19]}$. Moreover, temperature- and time-dependent ratcheting behaviors of non-metallic material, such as $\mathrm{PTFE}^{[20,21]}$, polycarbonate polymers ${ }^{[22]}$, polyacetal ${ }^{[23]}, \operatorname{PVDF}^{[24]}$, PEEK $^{[25]}$, non-asbestos fibre ${ }^{[26]}$ and so on, have also been investigated widely. Recently, micro- and macro-mechanisms of compression and recovery behavior of flexible graphite have been investigated by Toda et al. ${ }^{[27]}$. Results present that the 
microscopic compression/recovery behavior of flexible graphite is impacted by the highly localized deformation of thin expanded graphite discs, while its macroscopic deformation is induced by the combined effect of bending and thickness reduction of the discs. Chen et al. studied the dynamic mechanical behavior of flexible graphite made by exfoliated graphite ${ }^{[28]}$, which indicates the storage and loss moduli and the loss tangent under flexure are higher than those of under compression. Similarly, the dynamic compressive properties and failure mechanism under thermal cycles of graphite/epoxy composites have been tested by $\mathrm{Wosu}^{[29]}$ and $\mathrm{Shin}^{[30]}$. As for the sealing performance of graphite gaskets, Bramsiepe et al. ${ }^{[31]}$ proposed a combined laminar and branching capillaries model to improve the prediction accuracy of fugitive VOC emissions from liquid charged flange joints with graphite gaskets. The leakage rates of flexible graphite gasket reinforced with tanged metal sheet under room temperature was further tested by $\mathrm{Gu}$ et al. ${ }^{[32]}$, which can be used to assess the tightness of bolted flange or other sealing joints with RGSWSSI. Lee et al. ${ }^{[33]}$ developed a gasket-integrated carbon/silicone elastomer composite bipolar plate to enhance the sealing reliability of proton exchange membrane fuel cell system. Under high temperature condition, creep and stress relaxation of gaskets and bolts have significant effect on the sealing joints ${ }^{[34,35,36]}$. However, according to the best knowledge of authors, investigations on accumulated compressive deformation features of RGSWSSI are still very few, especially at elevated temperature. Hence, it is necessary to test the accumulated deformation of RGSWSSI systematically under cyclic compressive loads taking into consideration of various influence factors.

In this study, accumulated deformations of RGSWSSI are tested under cyclic stress-controlled compression from $500^{\circ} \mathrm{C}$ to $600^{\circ} \mathrm{C}$. The influences of insert type, temperature, stress amplitude, stress rate and loading sequence under multiple load steps are considered systematically. Moreover, the ratcheting effects of RGSWSSI are further discussed in detail based on the tested data.

\section{Experimental procedures}

The tested RGSWSSI are ring-shaped plate specimens and the geometrical 
dimensions and structures are shown in Fig.1 and Table 1. It should be noted that $r_{i}$ and $r_{o}$ are inner radius and outer radius, and $h$ is the thickness of specimen in Table 1. As shown in Table 1, a slight machining errors are produced due to the complexity of RGSWSSI. Correspondingly, the same peak stress is applied for each specimen to investigate the accumulated deformation. Five different types of specimens in Fig.1, which are composed of flexible graphite and thin stainless steel tanged insert or bonded insert, are tested in this work. Namely, Type 3564 specimen includes one-layered 304 stainless steel tanged insert, Type 3540 and 3885 specimens include one- and five-layered 316L stainless steel bonded inserts, and Type 3560 and 3865 specimens contain one- and two-layered 316L stainless steel tanged inserts. It should be noting that the thicknesses of each thin stainless steel tanged sheet and bonded sheet are $0.1 \mathrm{~mm}$ and $0.05 \mathrm{~mm}$, respectively. Moreover, the microscopic observation of the cross-section of flexible graphite part in RGSWSSI is also presented in Fig.1. We can clearly see that it is composed of compressed multilayered thin flexible graphite films, which is responsible for the sealing performance of RGSWSSI.

The test set-up is RPL50 creep-fatigue machine equipped with a self-designed compression-compression clamp for plate-shaped specimens, as shown in Fig.2. The designed compression-compression clamp is composed of five parts: lower and upper connecting rods, concave and convex spherical clamps and the flat clamp. It should be noted that the concave and convex spherical clamps are used to compensate the tiny deviation of axial load across the compressed surface of the specimen. The axial compressive displacement is tested by a tension-compression extensometer from room temperature to elevated temperature $\left(1100^{\circ} \mathrm{C}\right)$. To ensure the uniformity of temperature field through the whole specimen at high temperature, it is first heated to the maximum experimental temperature, and then held for 30 minutes before applying the compressive loading. Various cyclic stress-controlled loads are tested after the required temperature, and the experimental conditions of this work are also listed in Table 1.

\section{Results and Discussion}




\subsection{Cyclic nominal stress-strain curves of RGSWSSI}

The compressive stress-strain curves of RGSWSSI with different inserts under cyclic pulsating loads with the peak stress of $32 \mathrm{MPa}$, the stress rate of $0.5 \mathrm{MPa} / \mathrm{s}$ and the temperature of $500^{\circ} \mathrm{C}$ are shown in Fig.3. Noting that the stress and strain of this work represent the nominal stress and nominal strain, respectively, due to the inhomogeneity of RGSWSSI. For clear expression, all the tested nominal strain and nominal stress of this work are multiplied by -1 , although the cyclic compressive loads are applied during the testing process. Figs 3(a) to 3(c) present the typical stress-strain curves of Type 3885, Type 3560 and Type 3865 specimens for 200 cycles. Results show that the nominal stress-strain curves of three specimens during the first cycle are remarkably different from those curves in the subsequent cycles. Namely, the maximum compression rates during the first cycle are almost up to $38 \%$ for Type 3885 specimen and 50\% for Type 3560 and Type 3865 specimens, but turn to be very small in the subsequent cycles. However, the rebound curves of specimens for different cycles change slightly. Additionally, small opening of each cyclic stress-strain curve takes place, especially for about the first 10 cycles, which shifts the stress-strain curve to the right-hand direction with the increase of number of cycles. But the opening becomes smaller and smaller with increasing number of cycles due to the compressive hardening effect of specimens. It is worth noting that crescent-shaped stress-strain relationships can be observed for RGSWSSI, which is obviously different from those of other metal or non-metal materials, as shown in Fig.4. These may be induced by the slight geometrical irregularities of specimens, which is usually designed for ensuring a good compression-rebound performance.

According to the tested nominal stress-strain curves of RGSWSSI at the first cycle, the compressive modulus defined by the ratio of the peak stress to the peak strain can be calculated, as shown in Fig.5. It should be noted the compressive modulus almost keeps constant when the temperature range is from $500^{\circ} \mathrm{C}$ to $600^{\circ} \mathrm{C}$ for RGSWSSI with 316L stainless steel insert (Type 3540, Type 3885, Type 3560 and Type 3865), while it decreases significantly for that with 304 stainless steel insert (Type 3564 ). This caused by the different mechanical properties of $316 \mathrm{~L}$ and 304 
stainless steel materials at elevate temperature. Namely, the elastic modulus and yield stress of 304 stainless steel decrease more rapidly comparing with those of $316 \mathrm{~L}$ stainless steel when the temperature changes from $500^{\circ} \mathrm{C}$ to $600^{\circ} \mathrm{C}$. Moreover, the nominal compressive moduli between $500^{\circ} \mathrm{C}$ to $600^{\circ} \mathrm{C}$ for Type 3540, Type 3885, Type 3560 and Type 3865 specimens are approximately $64.83 \mathrm{MPa}, 85.62 \mathrm{MPa}$, 64.14MPa and 64.98MPa, respectively, under the peak compressive stress of $32 \mathrm{MPa}$.

\subsection{Accumulated deformation of RGSWSSI under cyclic pulsating loads}

In order to compare the accumulated compressive deformation of various types of RGSWSSI, the maximum axial compressive strains of each cycle at $500^{\circ} \mathrm{C}$ and $600^{\circ} \mathrm{C}$ are illustrated in Fig.6. Results show the accumulated compressive strain of Type 3885 is obviously less than that of other types. It is reasonable because five layered $316 \mathrm{~L}$ stainless steel sheets are inserted into the flexible graphite layer, which means the thickness of stainless steel insert is remarkably greater than that of the others. However, the accumulated compressive deformations for the other four types are very similar, and all of them approach to 50\%. Moreover, the accumulated compressive deformations of various specimens at $600^{\circ} \mathrm{C}$ are slightly greater than that at $500^{\circ} \mathrm{C}$. This is caused by the slight softening behavior of stainless steel insert with increasing the temperature.

To further discuss the effect of temperature on the accumulated deformation of specimens, the accumulative strains of Type 3865 and Type 3560 gaskets at $500^{\circ} \mathrm{C}$, $550^{\circ} \mathrm{C}$ and $600^{\circ} \mathrm{C}$ are depicted in Fig.7. Results clearly show that the accumulated deformation always enhances with increasing number of cycles at elevated temperatures, which means the obvious ratcheting effect takes place. However, the accumulated strain increases slightly when the temperature changes from $500^{\circ} \mathrm{C}$ to $600^{\circ} \mathrm{C}$, which indicates the temperature has only a little influence on the ratcheting effect between this temperature range.

Based on the accumulated strains from Figs 6 and 7, it is easy to find that the strain evolution with number of cycles increases rapidly during about the first 25 cycles, while it goes up slowly in the subsequent cycles. To illustrate the evolution of 
ratcheting strain clearly, the accumulated strain rates with number of cycles of Type 3560 specimen at $500^{\circ} \mathrm{C}, 550^{\circ} \mathrm{C}$ and $600^{\circ} \mathrm{C}$ are presented in Fig.8, and the strain ranges with number of cycles of Type 3865, Type 3560 and Type 3885 specimens at the nominal stress of $16 \mathrm{MPa}$ are shown Fig.9. Results evidently demonstrate that the ratcheting rate per cycle and strain range per cycle can be divided into two stages. In the primary stage, both of them reduces promptly in about the first 25 cycles, and then become steady with an almost constant ratcheting rate and strain range. Noting that the ratcheting rate and strain range of RGSWSSI during the steady stage are much less than that of in the primary stage at high temperature. Accordingly, the ratcheting effect should be stressed to assess the sealing performance or tightness of high-temperature bolted flange joints with RGSWSSI under harsh fluctuating loads.

\subsection{Accumulated deformation of Type 3865 specimen under small stress amplitude and creep}

In some operating conditions, small cyclic stress amplitudes are of greater interest in practical engineering. In the following work, Type 3865 specimen is used to test the accumulated strain under the cyclic compressive stress of $31 \pm 1 \mathrm{MPa}$ and the stress rate of $0.5 \mathrm{MPa} / \mathrm{s}$. The test is performed up to 2000 cycles to observe the evolution of ratcheting strains, as shown in Fig.10. Results present that still a little accumulated deformation occurs under small stress amplitude. Concretely, the peak strain is $48.99 \%$ at the first cycle, whereas it is $49.81 \%$ at the $2000^{\text {th }}$ cycle. Actually, the accumulated strain with small stress amplitude may be impacted by the creep effect $^{[4]}$. Therefore, the creep strains of Type 3865 specimen with the same peak stress of $32 \mathrm{MPa}$ at $500^{\circ} \mathrm{C}$ and $600^{\circ} \mathrm{C}$ are further tested, as shown in Fig.11. It can be obviously seen that the static compressive creep increases a little with the increment of temperature. the creep strain is $49.52 \%$ at $500^{\circ} \mathrm{C}$ when the holding time is 8 hours, but it becomes $51.71 \%$ at $500^{\circ} \mathrm{C}$ correspondingly.

To investigate the relationship between the static creep strain and the accumulated strain with small stress amplitude at the same run-time, the accumulated strain changing with time is obtained according to the stress rate and the calculated 
data is also superposed in Fig.11. Results show that the similar evolution rule of accumulated strain and creep strain with time can be found, and the accumulated strain with small stress amplitude very approaches to the corresponding creep strain at the same run-time. Therefore, the accumulated strain for RGSWSSI under fluctuating loads with small stress amplitude can be estimated approximately by the corresponding static creep strain in practical engineering with good accuracy at high temperature.

\subsection{Accumulated deformation of Type 3865 specimen under multiple load steps}

Taking into consideration of the randomness of fluctuating loads, it is necessary to investigate their cyclic compressive features under multiple load steps. In the following work, cyclic compressive experiments of three load steps with nominal stress of $16 \mathrm{MPa}, 20 \mathrm{MPa}$ and $24 \mathrm{MPa}$ step-by-step considering the influence of stress amplitude $\Delta \sigma$, stress rate $\dot{\sigma}$ and load sequence for RGSWSSI are conducted. Each nominal stress step is tested up to 100 cycles to observe the steady ratcheting effect. Since the accumulated deformations of various types of RGSWSSI are very similar to each other from the above observations, the Type 3865 specimens are chosen to study the deformations under multiple load steps.

Fig.12 illustrates cyclic compressive stress-strain curves of Type 3865 specimens under different stress amplitudes of $8 \mathrm{MPa}, 4 \mathrm{MPa}$ and $2 \mathrm{MPa}$, respectively. Noting that the same stress rate of $0.5 \mathrm{MPa} / \mathrm{s}$ and the same temperature of $500^{\circ} \mathrm{C}$ are applied for each load step. From the Fig.12, it is clearly presented that even if the small stress amplitude is applied, the slight opening behavior of cyclic stress-strain curves can also be found, and the plastic deformation will be accumulated correspondingly under these cases. It is of interest that the cyclic stress-strain relationship of RGSWSSI with small stress amplitude is no longer crescent-shaped, but is similar to the stress-strain curve of general metallic materials. This may be induced by the higher density or more uniform geometry of the tested specimen due to the previous compression load. Moreover, the accumulated compressive strain of Type 3865 specimen under three load steps with different stress amplitudes is shown 
in Fig.13. Results indicate the accumulated compressive strain increases with enhancing the stress amplitude obviously. It should be noted that the evolution of accumulated compressive strain for each load step can be divided into two stages. The accumulated compressive strain only increases during about the first 25 cycles (Stage I), and then the plastic strain increment is less than $10^{-4} /$ cycle in the subsequent cycles (Stage II). This indicates that the plastic strain approximately remains constant during the Stage II. Additionally, Asada and Yamashita ${ }^{[37]}$ proposed an alternative shakedown evaluation approach, which considers that if the plastic strain increment always reduces with increasing number of cycles, the shakedown boundary can be estimated when the plastic strain increment is less than $10^{-4} /$ cycle. This means that RGSWSSI always turn to shakedown during the Stage II. It is of great interest that the accumulated compressive strain increases linearly with increasing the stress amplitude in a logarithmic coordinates under different number of cycles and load steps, as shown in Fig.13(b). This indicates that the accumulated compressive strain can be extrapolated easily in practical engineering design.

To investigate the loading sequence effect on the accumulated deformation of Type 3865 specimen, two loading sequences with different nominal stress steps of $16 \mathrm{MPa}, 20 \mathrm{MPa}$ and $24 \mathrm{MPa}$ step-by-step (low to high) as well as $24 \mathrm{MPa}, 20 \mathrm{MPa}$ and $16 \mathrm{MPa}$ step-by-step (high to low) at $\Delta \sigma=4 \mathrm{MPa}, \dot{\sigma}=0.5 \mathrm{MPa} / \mathrm{s}$ and $\mathrm{T}=500^{\circ} \mathrm{C}$ are tested, as shown in Fig.14. The figure clearly illustrates that the accumulated strain increases with the increment of load step for the low to high path, while it slightly decreases with the increase of load step for the high to low path due to the compression hardening effect. Although obvious difference of the evolutions of accumulated strains can be found for the two load sequences, the accumulated ratcheting strains at the end of the third step for the two load paths are very close to each other. Concretely, the accumulated deformation obtained by the high to low path is slightly greater than that of the low to high path, and the corresponding accumulated strains are $46.50 \%$ and $45.96 \%$, respectively.

Accumulated compressive strains of Type 3865 specimen under three load steps with different stress rates of $0.25 \mathrm{MPa} / \mathrm{s}, 0.5 \mathrm{MPa} / \mathrm{s}, 1 \mathrm{MPa} / \mathrm{s}$, and $2 \mathrm{MPa} / \mathrm{s}$ are presented 
in Fig.15. Noting that the same stress amplitude of $4 \mathrm{MPa}$ and the same temperature of $500^{\circ} \mathrm{C}$ are applied for each load step. Results clearly illustrate that the accumulated deformations under these four cases are very close to each other. This implies that the accumulated compressive strain of RGSWSSI is almost rate-independent when the temperature is equal to and less than $500^{\circ} \mathrm{C}$. Rhee et al. tested the compressive properties of carbon fiber-reinforced composite in a submarine environment, which shows the compressive strain decreases slightly as the strain rate increases ${ }^{[38]}$. The similar phenomenon was also observed by Wosu $^{[27]}$ based on the dynamic compressive behavior of graphite/epoxy composite material below $160^{\circ} \mathrm{C}$. It is of great interest that the accumulated deformations under the above multiple step loading only increase with number of cycles before about the first 25 cycles for each step, then the plastic strain increment becomes almost less than $10^{-4} /$ cycle during the subsequent cycles under various stress rates. This means the shakedown behavior always takes place after about the initial 25 cycles. Accordingly, the high-temperature flange joint with RGSWSSI should be retightened after about the first 25 or more cycles under fluctuating load with small stress amplitude to ensure its sealing performance and tightness.

\section{Conclusions}

Accumulated deformations of RGSWSSI are tested under cyclic stress-controlled compression systematically. The main conclusions include:

(1) The accumulated compressive strain of RGSWSSI is almost rate-independent when the temperature is equal to and less than $500^{\circ} \mathrm{C}$. However, it always enhances with increasing number of cycles under pulsating compression with the peak stress of $32 \mathrm{MPa}$ at $500^{\circ} \mathrm{C}$ or higher. It is of interest that the specimens with tanged insert and bonded insert have very similar deformation features under the same load. Moreover, the shakedown behavior of RGSWSSI always takes place under small stress amplitude after the first 25 cycles. Noting that the accumulated strain for RGSWSSI with small stress amplitude very approaches to the static creep stain at the same peak stress and high temperature. 
(2) The crescent-shaped stress-strain relationship is observed for RGSWSSI under cyclic pulsating compression due to the slight geometrical irregularities of specimens. However, the stress-strain curve of RGSWSSI under small stress amplitude is similar to the relationship of stainless steel owing to the previous compression hardening effect. Additionally, the compressive modulus almost maintains constant when the temperature changes from $500^{\circ} \mathrm{C}$ to $600^{\circ} \mathrm{C}$ for RGSWSSI with 316L stainless steel insert, while it decreases remarkably for that with 304 insert. This is because the elastic modulus and yield stress of 304 stainless steel decrease more rapidly compared with those of $316 \mathrm{~L}$ steel at elevated temperature.

\section{Acknowledgments}

This work was financially supported by the National Natural Science Foundation of China (51305310), Hubei Provincial Department of Education Science and Technology Research Program (D20161508), and the China Scholarship Council (201608420201). 


\section{References}

[1] Celzard A, Marêché JF, Furdin G. Modelling of exfoliated graphite. Prog Mater Sci. 2005; 50: 93-179.

[2] Bramsiepe C, Pansegrau L, Schembecker G. A model to predict fugitive VOC emissions from liquid charged flange joints with graphite gaskets. Chem Eng J. 2010; 159: 11-16.

[3] Zheng XT, Wen X, Wang W, Gao JY, Lin W, Ma LW, Yu JY. Creep-ratcheting behavior of PTFE gaskets under various temperatures. Polym Test. 2017; 60: 229-235.

[4] Zheng XT, Wen X, Gao JY, Yu JY, Lin W, Xu JM. Temperature-dependent ratcheting of PTFE gaskets under cyclic compressive loads with small stress amplitude. Polym Test. 2017; 57: 296-301.

[5] Zheng XT, Wang HY, Wang W, Lin W, Ma LW, Xu JM,Yu JY. Compressive ratcheting effect of expanded PTFE considering multiple load paths. Polym Test. $2017 ; 61: 93-99$.

[6]Kang GZ, Zhang J, Sun YY, Kan QH. Uniaxial time-dependent ratcheting of SS304 stainless steel at high temperatures. J Iron Steel Res Int. 2007; 14: 53-59.

[7] Zheng XT, Wu KW, Wang W, Yu JY. Low cycle fatigue and ratcheting behavior of 35CrMo structural steel at elevated temperature. Nucl Eng Des. 2017; 314 : 285-292.

[8] Zheng X, Wang J, Gao J, Ma L, Yu J, Xu J. Rate-dependent low cycle fatigue and ratcheting of $25 \mathrm{Cr} 2 \mathrm{MoVA}$ steel under cyclic pulsating tension. Mater High Temp. 2017; https://doi.org/10.1080/09603409.2017.1386922.

[9] Wang W, Zheng X, Yu J, Lin W, Wang C, Xu J. Time-dependent ratcheting of 35CrMo structural steel at elevated temperature considering stress rates. Mater High Temp. 2016; 34:172-178.

[10] Chen X, Jiao R. Modified kinematic hardening rule for multiaxial ratcheting prediction. Int J Plasticity. 2004;20: 871-898.

[11] Chen X, Jiao R, Kim KS. On the Ohno-Wang kinematic hardening rules for 
multiaxial ratcheting modeling of medium carbon steel. Int J Plasticity. 2005; 21: 161-184.

[12] Zhang SL, Xuan FZ, Guo SJ, Zhao P. The role of anelastic recovery in the creep-fatigue interaction of $9-12 \% \mathrm{Cr}$ steel at high temperature. Int $\mathrm{J}$ Mech Sci. 2017;122: 95-103.

[13] Zhao P, Xuan FZ and Wu DL. Cyclic softening behaviors of modified 9-12\% Cr steel under different loading modes: role of loading levels. Int J Mech Sci 2017; 131-132: 278-285.

[14] Zhang SL and Xuan FZ. Interaction of cyclic softening and stress relaxation of 9-12\% $\mathrm{Cr}$ steel under strain-controlled fatigue-creep condition: experimental and modeling. Int J Plasticity 2017; 98: 45-64.

[15] Wu DL, Xuan FZ, Guo SJ, Zhao P. Uniaxial mean stress relaxation of 9-12\% Cr steel at high temperature: Experiments and viscoplastic constitutive modeling. Int J Plasticity. 2016; 77: 156-173.

[16] Zheng XT, Xuan FZ. Shakedown analysis of multilayered beams coupled with ductile damage. Nucl Eng Des. 2012; 250: 14-22.

[17] Zheng XT, Peng CF, Yu JY, Wang CG, Lin W. A unified shakedown assessment method for butt welded joints with various weld groove shapes. ASME J Pres Ves Tech. 2015; 137: \#021404.

[18]Zheng XT, Peng HY, Yu JY, Lin W, Xu JM. Analytical ratchet limit for pressurized pipeline under cyclic nonproportional loadings. J Pipeline Syst Eng Prac. 2017; 8: 04017002.

[19]Zheng XT, Wang JQ, Wang W, Ma LW, Lin W, Yu JY. Elastic-plastic-creep response of multilayered systems under cyclic thermo-mechanical loadings. J Mech Sci Technol. 2018; 32: 1227-1234.

[ 20 ] Zhang Z, Chen X, Wang YP. Uniaxial ratcheting behavior of polytetrafluoroethylene at elevated temperature. Polym Test. 2010; 29: 352-357.

[21] Zheng XT, Zhang XH, Ma LW, Lin W, Yu JY, Xu JM. Rate-dependent mechanical characteristics of polytetrafluoroethylene (PTFE) gaskets under cyclic 
pulsating compression. Polym Bull. 2018; 1: 1-14.

[22] Xi C, Kang GZ, Lu F, Zhang J, Jiang H. An experimental study on uniaxial ratcheting of polycarbonate polymers with different molecular weights. Mater Des. 2015; 67: 644-648.

[23] Shariati M, Hatami H, Yarahmadi H, Eipakchi HR. An experimental study on the ratcheting and fatigue behavior of polyacetal under uniaxial cyclic loading. Mater Des. 2012; 34: 302-312.

[24] Chen G, Lin Q, Chen S, Chen X. In-plane biaxial ratcheting behavior of PVDF UF membrane. Polym Test. 2016; 50: 41-48.

[25] Shrestha R, Simsiriwong J, Shamsaei N. Cyclic deformation and fatigue behavior of polyether ether ketone (PEEK). Int J Fatigue. 2016; 82: 411-427.

[26] Zheng XT, Dai WC, Ma LW, Wang W, Lin W, Yu JY. Compressive ratcheting and creep of non-asbestos fibre composite considering temperature effect. J Composite Mater. 2018; 2018:DOI: 10.1177/0021998318766227.

[27] Toda H, Tsubone K, Shimizu K, Uesugi K. Compression and recovery micro-mechanisms in flexible graphite. Carbon. 2013; 59: 184-191.

[28] Chen PH, Chung DDL. Dynamic mechanical behavior of flexible graphite made from exfoliated graphite. Carbon. 2012; 50: 283-289.

[29] Wosu SN, Hui D, Daniel L. Hygrothermal effects on the dynamic compressive properties of graphite/epoxy composite material. Compos Part B-Eng. 2016; 43: 841-855.

[30] Shin KB, Kim CG, Hong CS, Lee HH. Prediction of failure thermal cycles in graphite/epoxy composite materials under simulated low earth orbit environments. Compos Part B-Eng. 2000; 31: 223-235.

[31] Bramsiepe C, Pansegrau L, Schembecker G. A model to predict fugitive VOC emissions from liquid charged flange joints with graphite gaskets. Chem Eng J. 2010; 159: 11-16.

[32] Gu BQ, Chen Y, Zhu DS. Prediction of leakage rates through sealing connections with nonmetallic gaskets. Chin J Chem Eng. 2007; 15: 837-841. 
[33] Lee DY, Lim JW, Nam S, Choi I, Lee DG. Gasket-integrated carbon/silicone elastomer composite bipolar plate for high-temperature PEMFC. Compos Struct. 2015; 128: $284-290$.

[34] Guo JQ, Zheng XT, Zhang Y, Shi HC, Meng WZ. A Unified Continuum Damage Mechanics Model for Predicting the Stress Relaxation Behavior of High-Temperature Bolting. J Pressure Vessel Technol. 2014; 136: 011203.

[35] Guo JQ, Li F, Zheng XT, Shi HC, Meng WZ. An accelerated method for creep prediction from short term stress relaxation tests. J Pressure Vessel Technol. 2016, 138: 031401.

[36] Guo JQ, Meng WZ, Zheng XT, Tian L, Shi HC. Prediction of stress relaxation from creep data in terms of average creep rate. J Strain Anal Eng Des. 2015; $50: 15-24$.

[37] Asada S, Yamashita N, Okamoto A, Nishiguchi I. Verification of alternative criteria for shakedown evaluation using flat head vessel. In: ASME Pressure Vessels \& Piping Conference, Vancouver, British Columbia, Canada, August 5-9, 2002, Paper no. PVP2002-1217, pp.17-22. New York: ASME.

[38] Rhee KY, Kim HJ, Park SJ. Effect of strain rate on the compressive properties of graphite/epoxy composite in a submarine environment. Compos Part B-Eng. 2006; 37: $21-25$. 
Table 1. Geometrical dimensions and loading conditions of RGSWI specimens.

\begin{tabular}{|c|c|c|c|c|c|c|c|}
\hline \multirow[t]{2}{*}{$\mathbf{S N}$} & \multirow{2}{*}{$\begin{array}{l}\text { Gasket } \\
\text { Type }\end{array}$} & \multirow{2}{*}{$\begin{array}{c}\text { Temperature } \\
\left({ }^{\circ} \mathrm{C}\right)\end{array}$} & \multirow{2}{*}{$\begin{array}{c}\text { Stress } \\
\text { Rate } \\
(\mathrm{MPa} / \mathbf{s})\end{array}$} & \multicolumn{3}{|c|}{$\begin{array}{l}\text { Load paths (mean stress } \pm \\
\text { stress amplitude) (MPa) }\end{array}$} & \multirow{2}{*}{$\begin{array}{c}\text { Geometrical } \\
\text { Parameters } \\
r_{i} / r_{o} / h(\mathrm{~mm})\end{array}$} \\
\hline & & & & Stage 1 & Stage 2 & Stage 3 & \\
\hline 1 & \multirow{2}{*}{3540} & 500 & \multirow{12}{*}{0.5} & \multirow{12}{*}{$16 \pm 16$} & \multirow{12}{*}{ l } & \multirow{12}{*}{ l } & $21.48 / 47.03 / 3.01$ \\
\hline 2 & & 600 & & & & & $21.31 / 46.99 / 3.08$ \\
\hline 3 & \multirow{2}{*}{3885} & 500 & & & & & $21.36 / 46.99 / 3.05$ \\
\hline 4 & & 600 & & & & & $21.44 / 46.93 / 3.07$ \\
\hline 5 & \multirow{3}{*}{3564} & 500 & & & & & $21.40 / 47.09 / 3.08$ \\
\hline 6 & & 600 & & & & & $21.47 / 46.96 / 3.08$ \\
\hline 7 & & 500 & & & & & $21.52 / 47.10 / 3.09$ \\
\hline 8 & \multirow[t]{10}{*}{3560} & 550 & & & & & $21.37 / 47.08 / 3.05$ \\
\hline 9 & & 600 & & & & & $21.50 / 46.94 / 3.08$ \\
\hline 10 & & 500 & & & & & $21.41 / 47.02 / 3.13$ \\
\hline 11 & & 550 & & & & & $21.43 / 47.34 / 3.11$ \\
\hline 12 & & 600 & & & & & $21.35 / 47.02 / 3.15$ \\
\hline 13 & & $\mathrm{RT}$ & \multirow{4}{*}{0.5} & \multirow{4}{*}{$16 \pm 4$} & \multirow{4}{*}{$20 \pm 4$} & \multirow{4}{*}{$24 \pm 4$} & $21.35 / 47.08 / 3.10$ \\
\hline 14 & & 200 & & & & & $21.27 / 47.11 / 3.12$ \\
\hline 15 & & 400 & & & & & $21.34 / 47.12 / 3.10$ \\
\hline 16 & & 500 & & & & & $21.33 / 47.05 / 3.10$ \\
\hline 17 & & \multirow{4}{*}{500} & \multirow{4}{*}{0.5} & $16 \pm 2$ & $20 \pm 2$ & $24 \pm 2$ & $21.30 / 47.08 / 3.10$ \\
\hline 18 & \multirow[t]{9}{*}{3865} & & & $16 \pm 4$ & $20 \pm 4$ & $24 \pm 4$ & $21.33 / 47.05 / 3.10$ \\
\hline 19 & & & & $16 \pm 8$ & $20 \pm 8$ & $24 \pm 8$ & $21.36 / 47.13 / 3.11$ \\
\hline 20 & & & & $24 \pm 4$ & $20 \pm 4$ & $16 \pm 4$ & $21.47 / 47.16 / 3.13$ \\
\hline 21 & & & 0.25 & & & & $21.39 / 47.05 / 3.09$ \\
\hline 22 & & 500 & 1 & $16 \pm 4$ & $20 \pm 4$ & $24 \pm 4$ & $21.33 / 47.05 / 3.10$ \\
\hline 23 & & & 2 & & & & $21.48 / 47.21 / 3.13$ \\
\hline 24 & & 500 & & $31 \pm 1$ & I & I & $21.51 / 47.27 / 3.08$ \\
\hline 25 & & 600 & 0.5 & 32 & / & l & $21.51 / 47.35 / 3.06$ \\
\hline 26 & & 500 & & 32 & l & l & $21.41 / 47.21 / 3.08$ \\
\hline
\end{tabular}




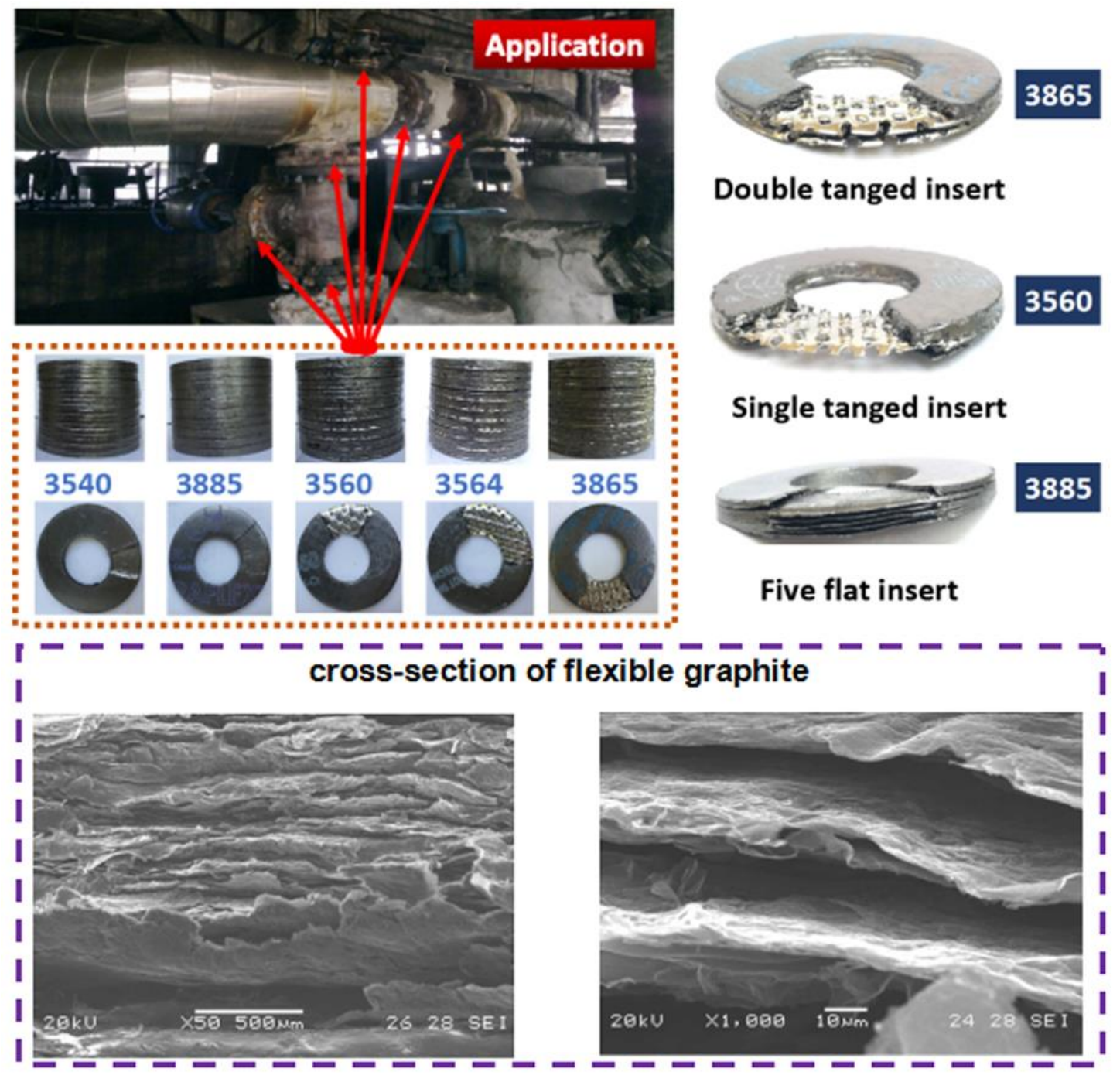

Figure 1. RGSWSSI and application in engineering. 


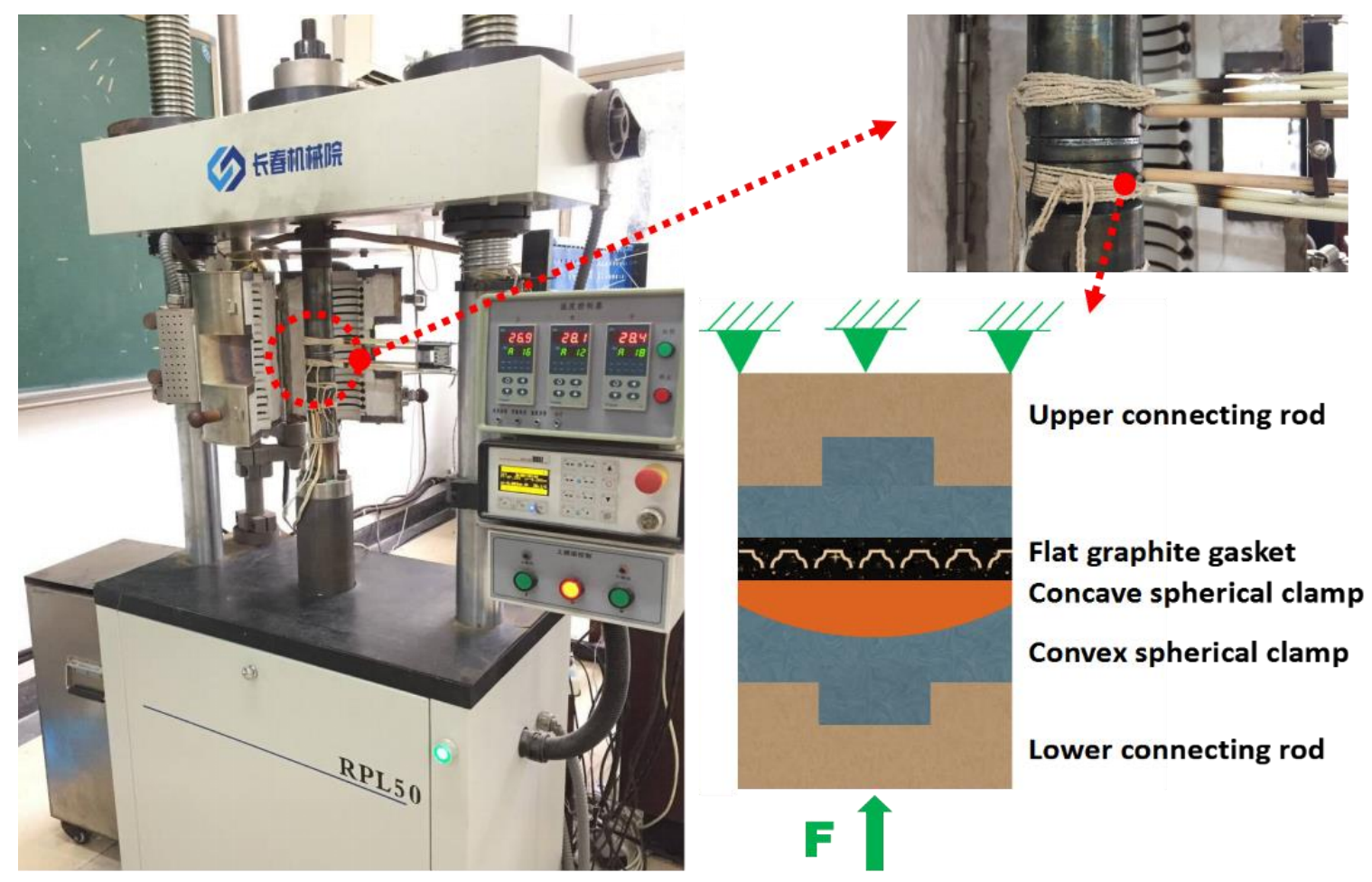

Figure 2. Testing set-up. 

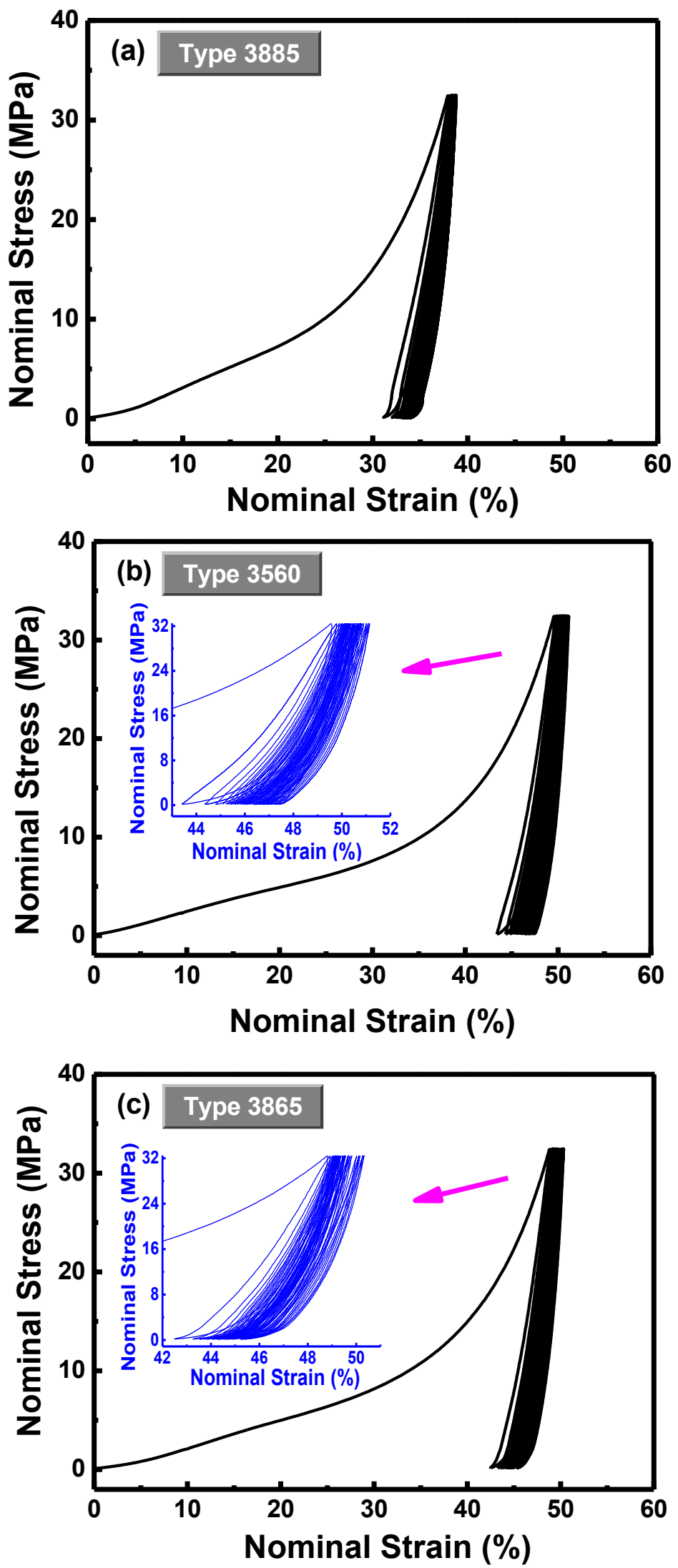

Figure 3. Cyclic compressive nominal stress-strain curves of RGSWSSI at $500^{\circ} \mathrm{C}$; (a) Type 3885, (b) Type 3560, (c) Type 3865 

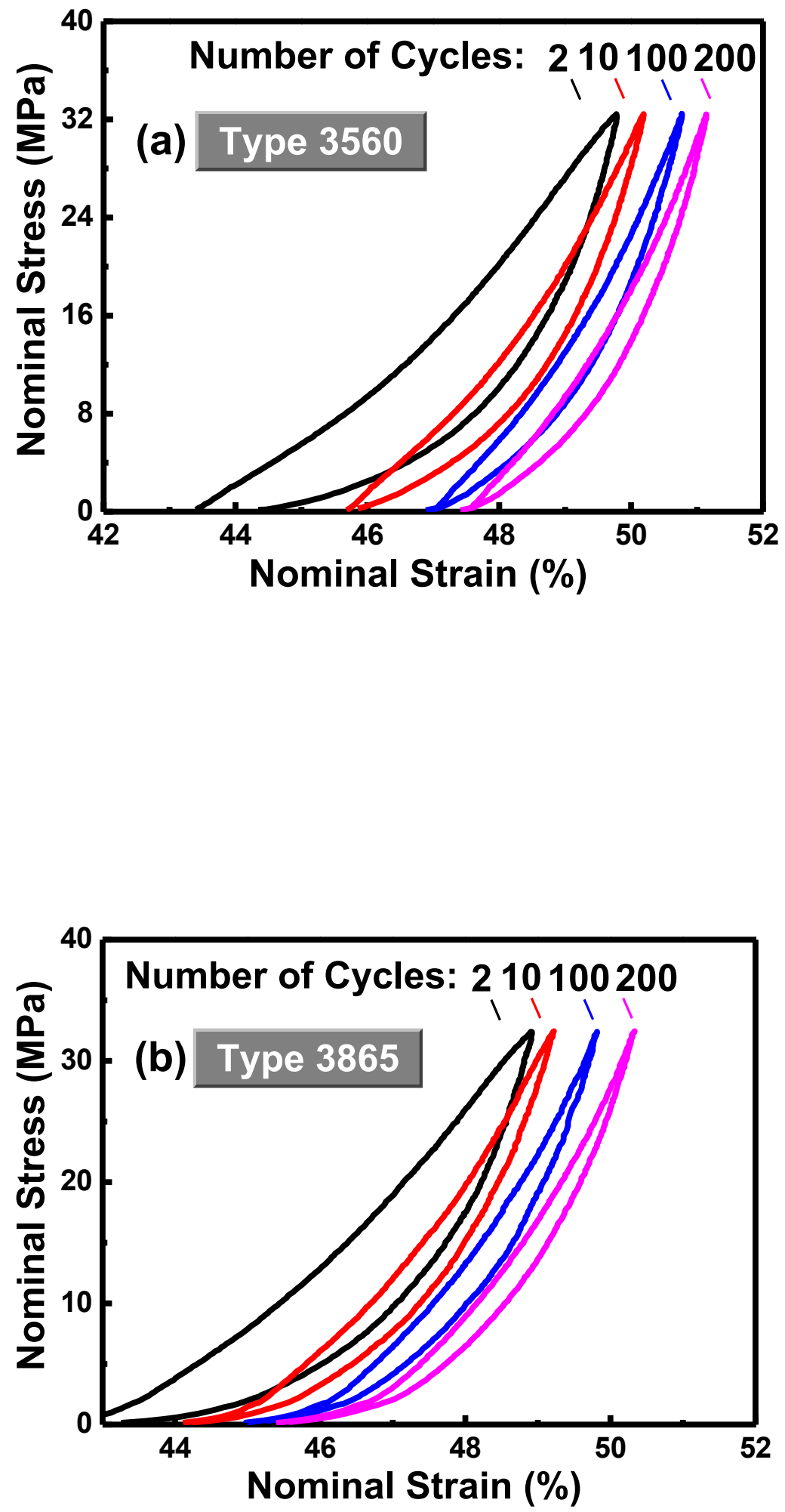

Figure 4. Crescent-shaped stress-strain relationship of RGSWSSI at $500^{\circ} \mathrm{C}$; (a) Type 3560, (b) Type 3865 


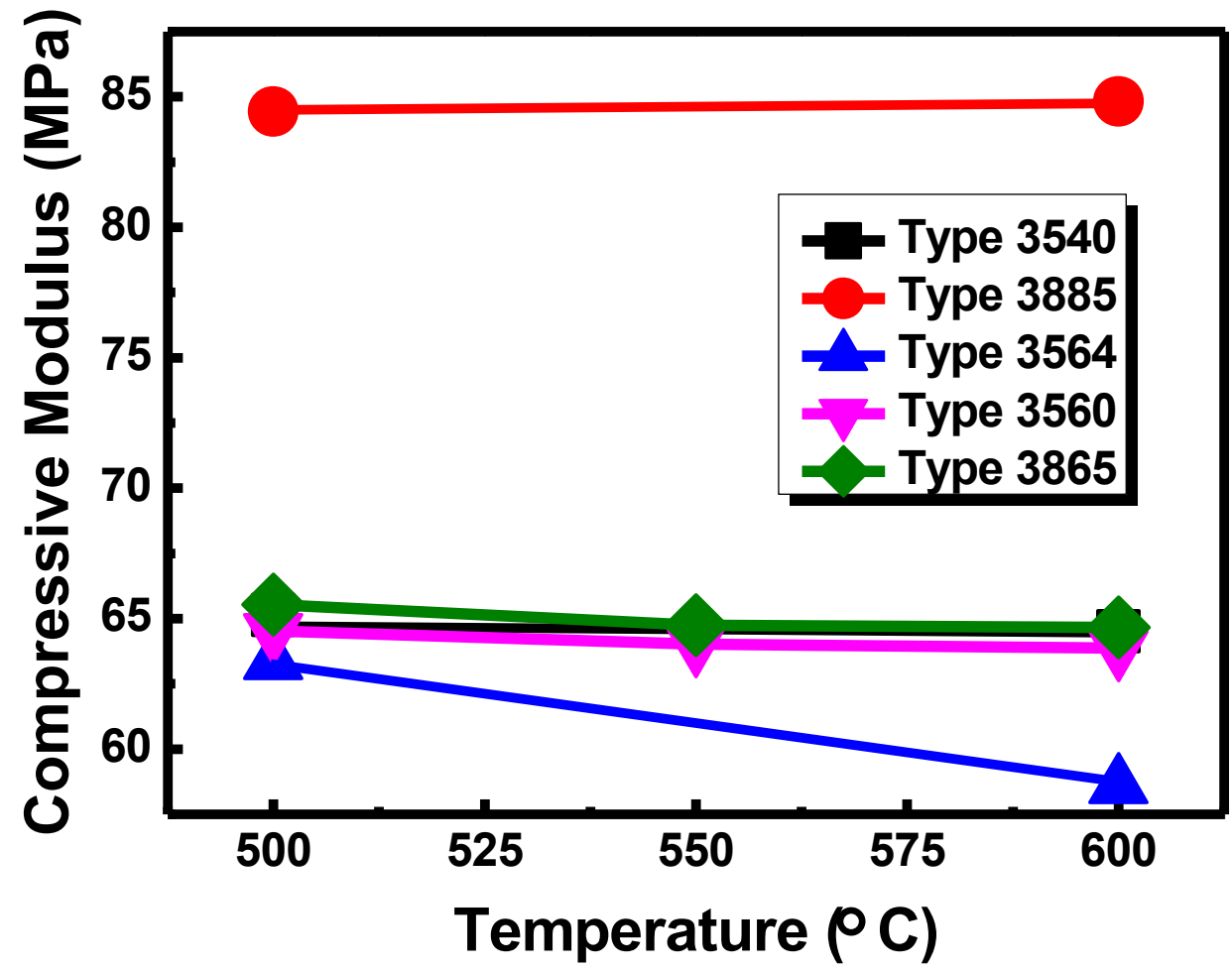

Figure 5. Compressive modulus of RGSWSSI under different temperatures. 

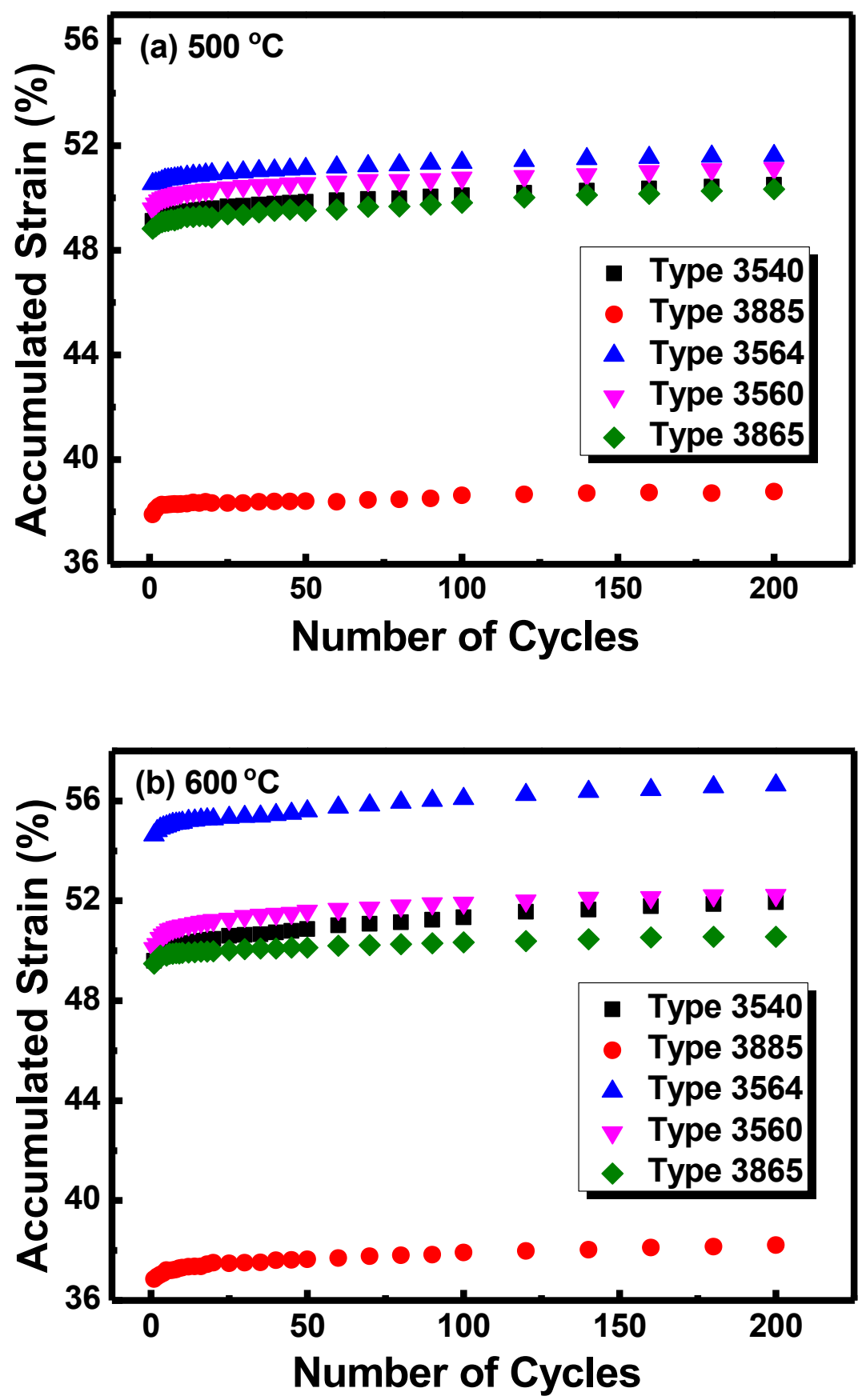

Figure 6. Accumulated compressive deformation of RGSWSSI at $500^{\circ} \mathrm{C}$ and $600^{\circ} \mathrm{C}$;

(a) $500^{\circ} \mathrm{C}$, (b) $600^{\circ} \mathrm{C}$ 

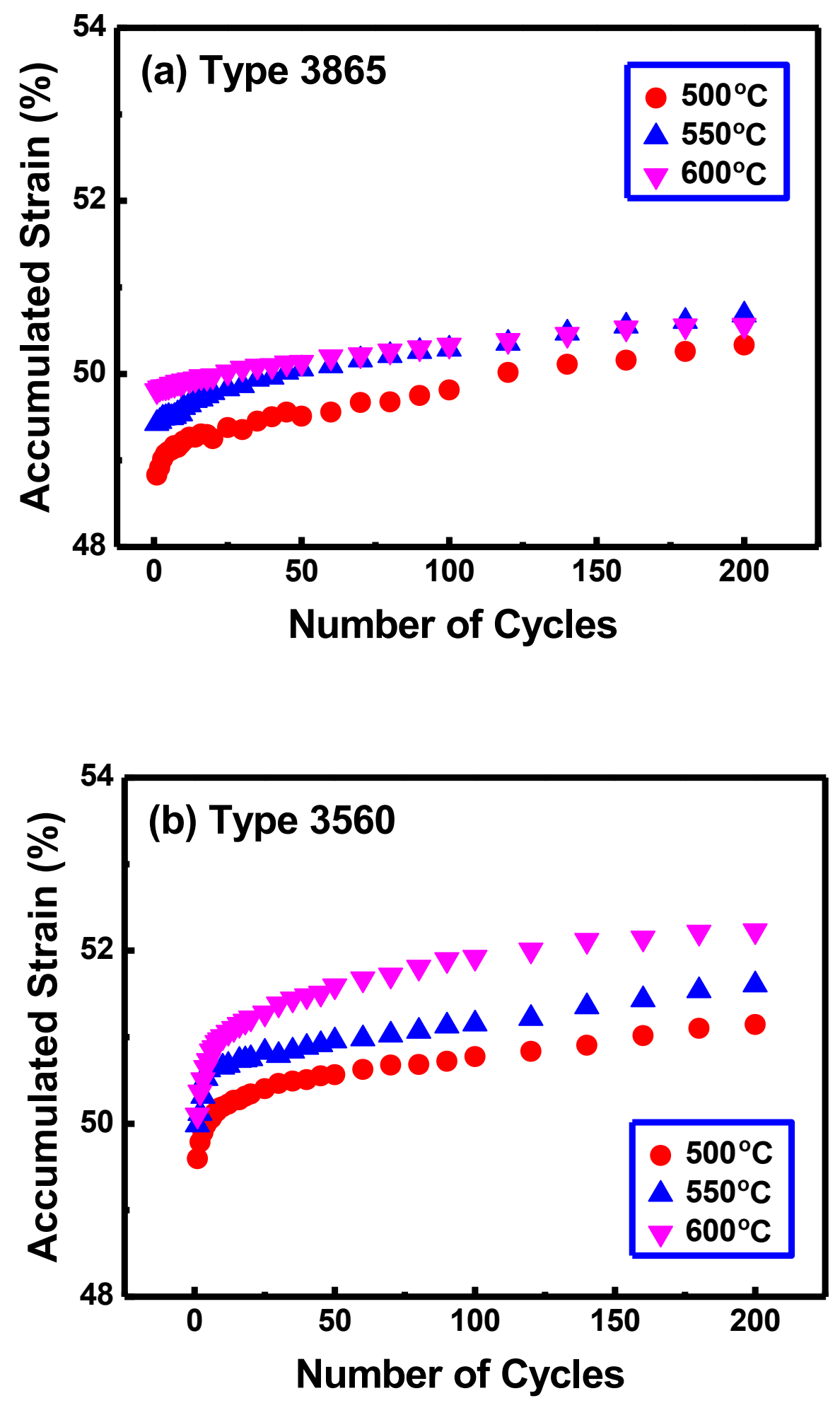

Figure 7. Accumulated compressive deformation of RGSWSSI at different temperatures; (a) Type 3865, (b) Type 3560 


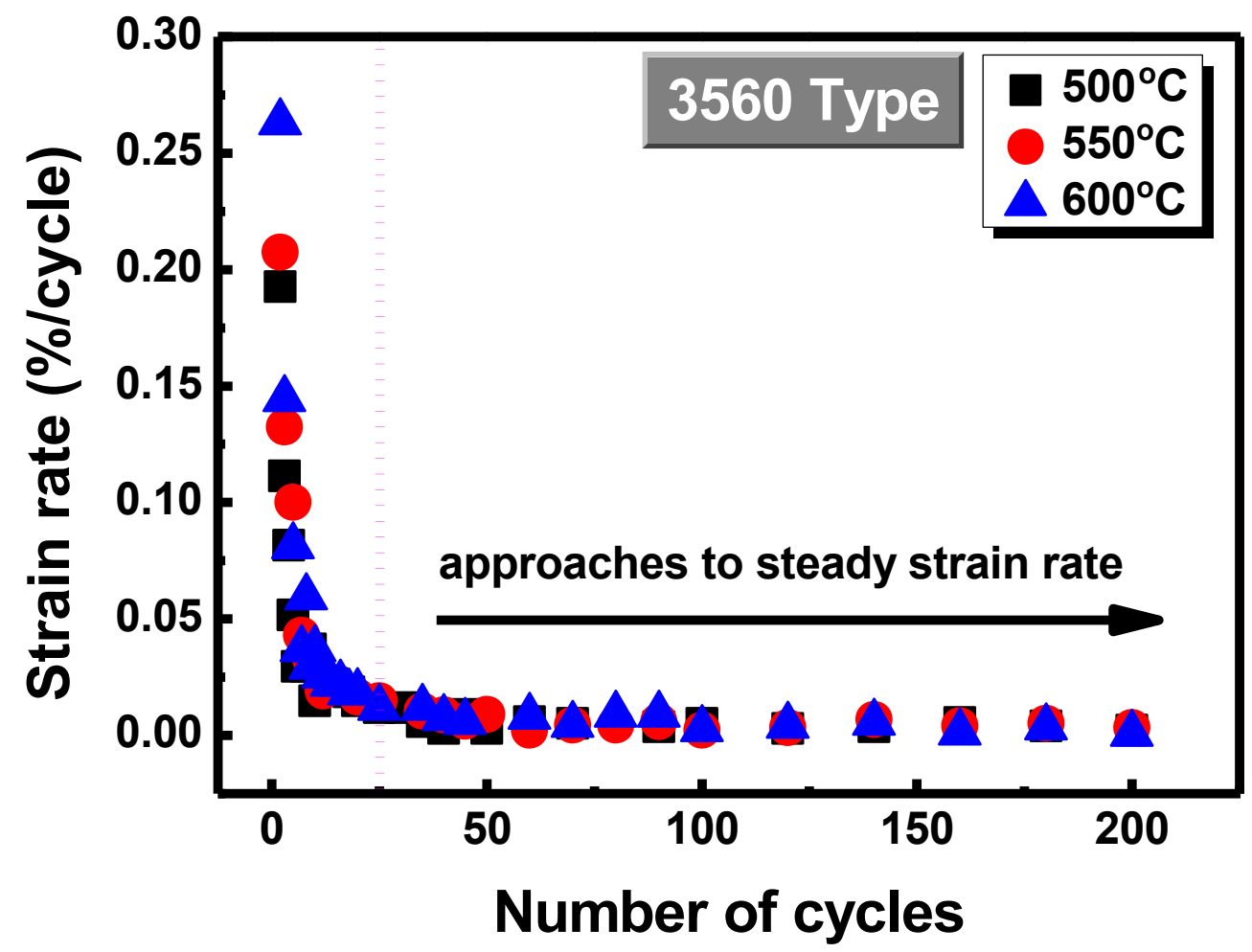

Figure 8. Evolution of strain rate with number of cycles of Type 3560 specimen under different temperatures. 


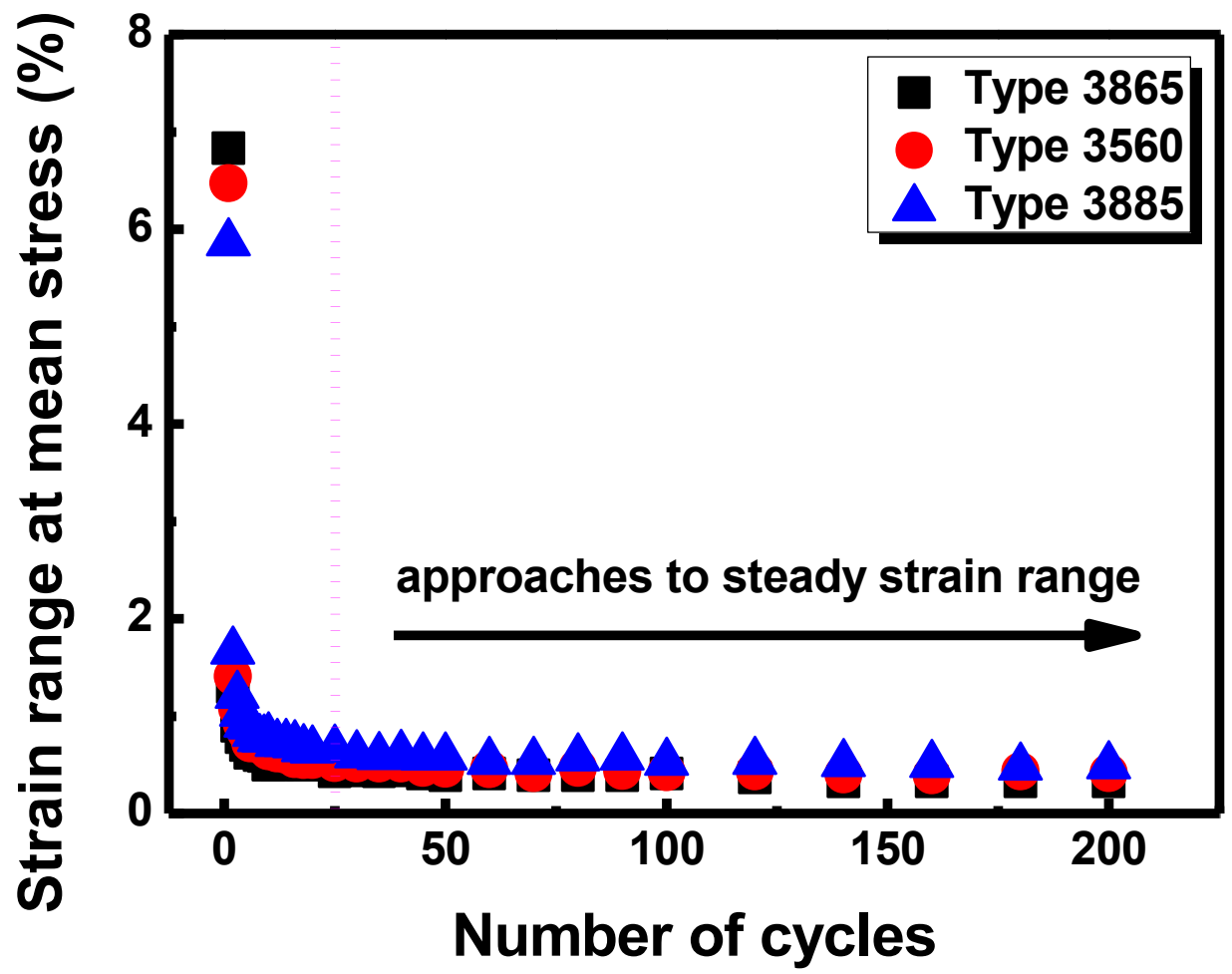

Figure 9. Strain range evolution with number of cycles at the mean stress of $16 \mathrm{MPa}$ and at $500^{\circ} \mathrm{C}$. 


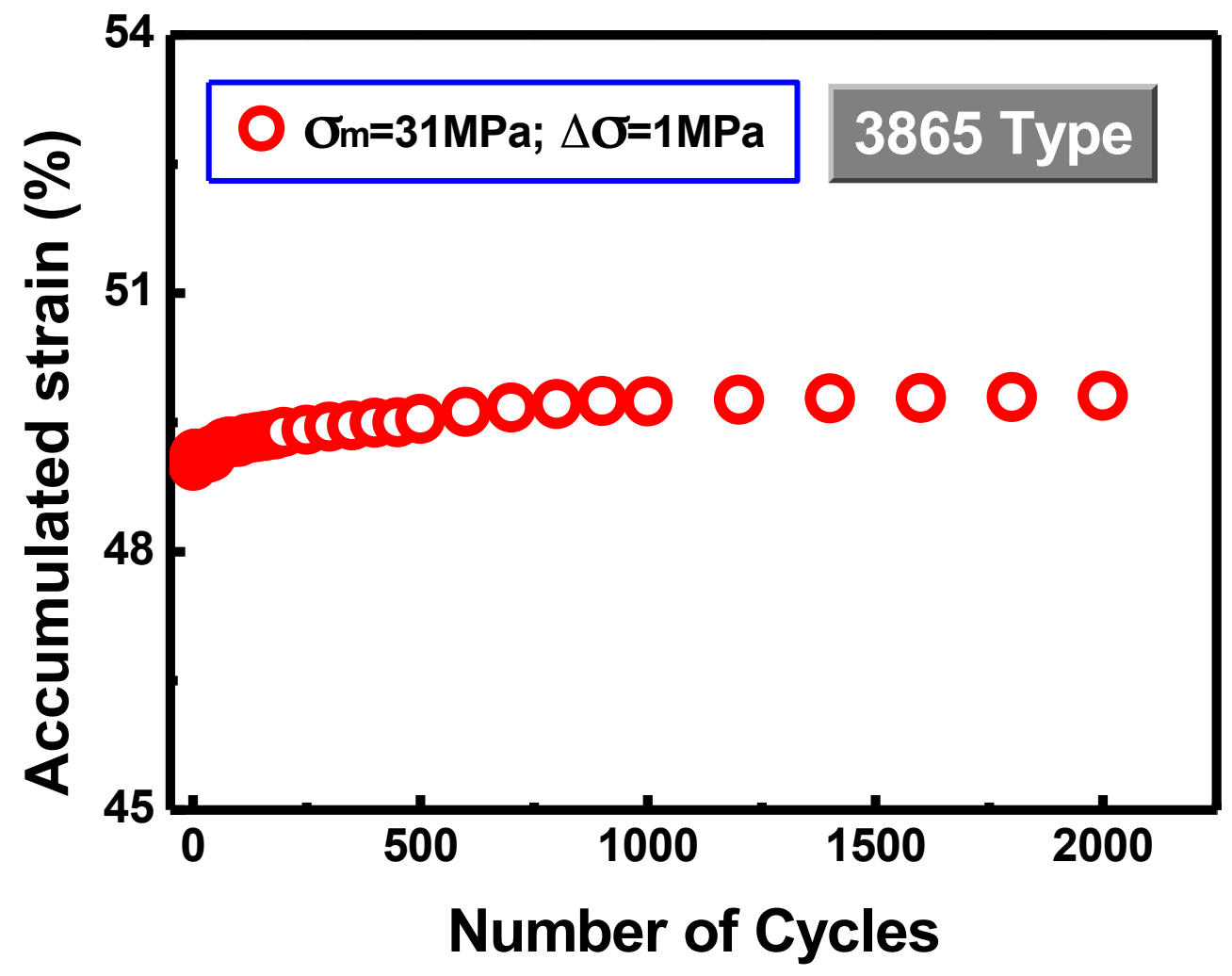

Figure 10. Accumulated compressive deformation of Type 3865 specimen with small stress amplitude at $500^{\circ} \mathrm{C}$. 


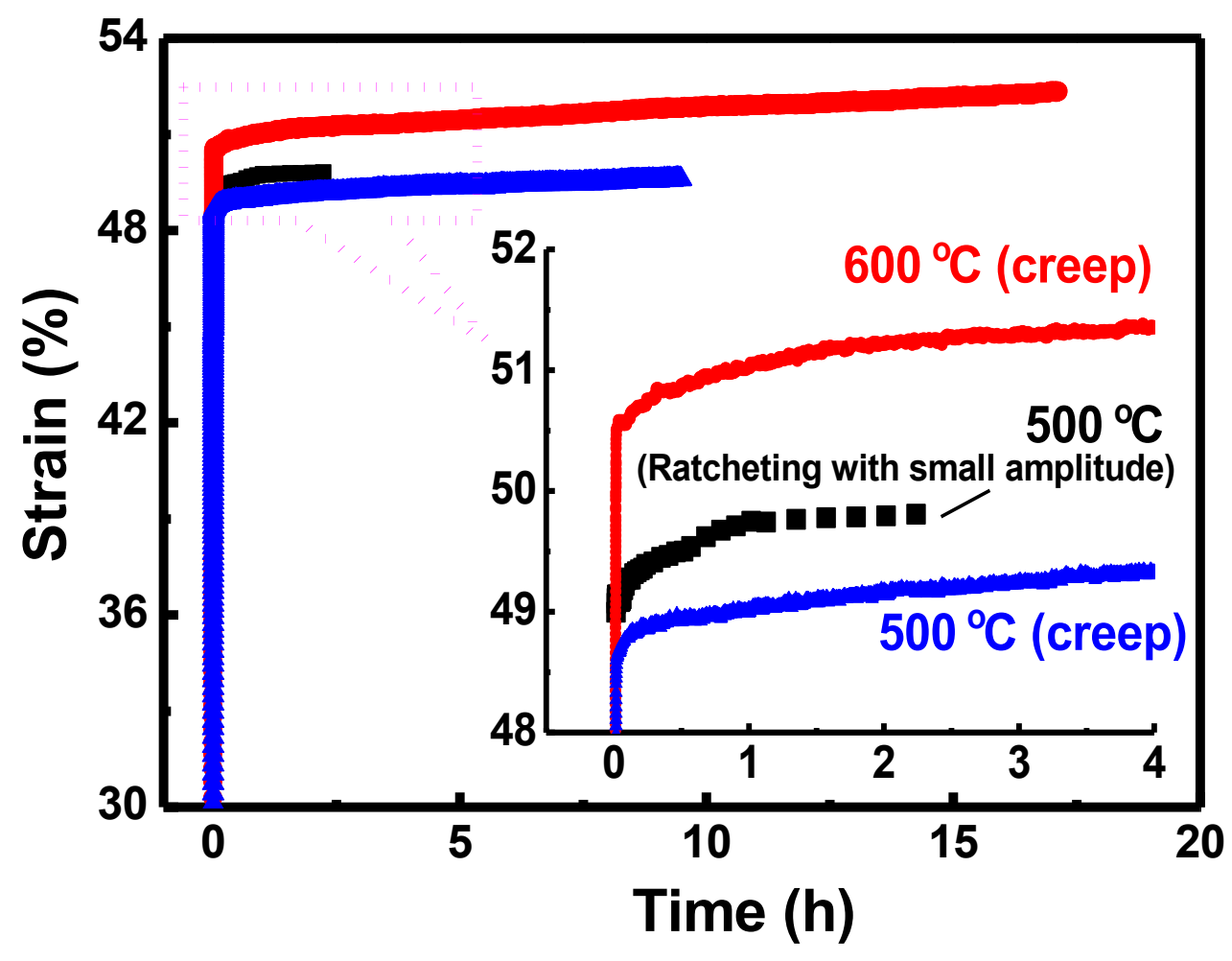

Figure 11. Creep strain and accumulated strain with small stress amplitude of Type 3865 specimen. 

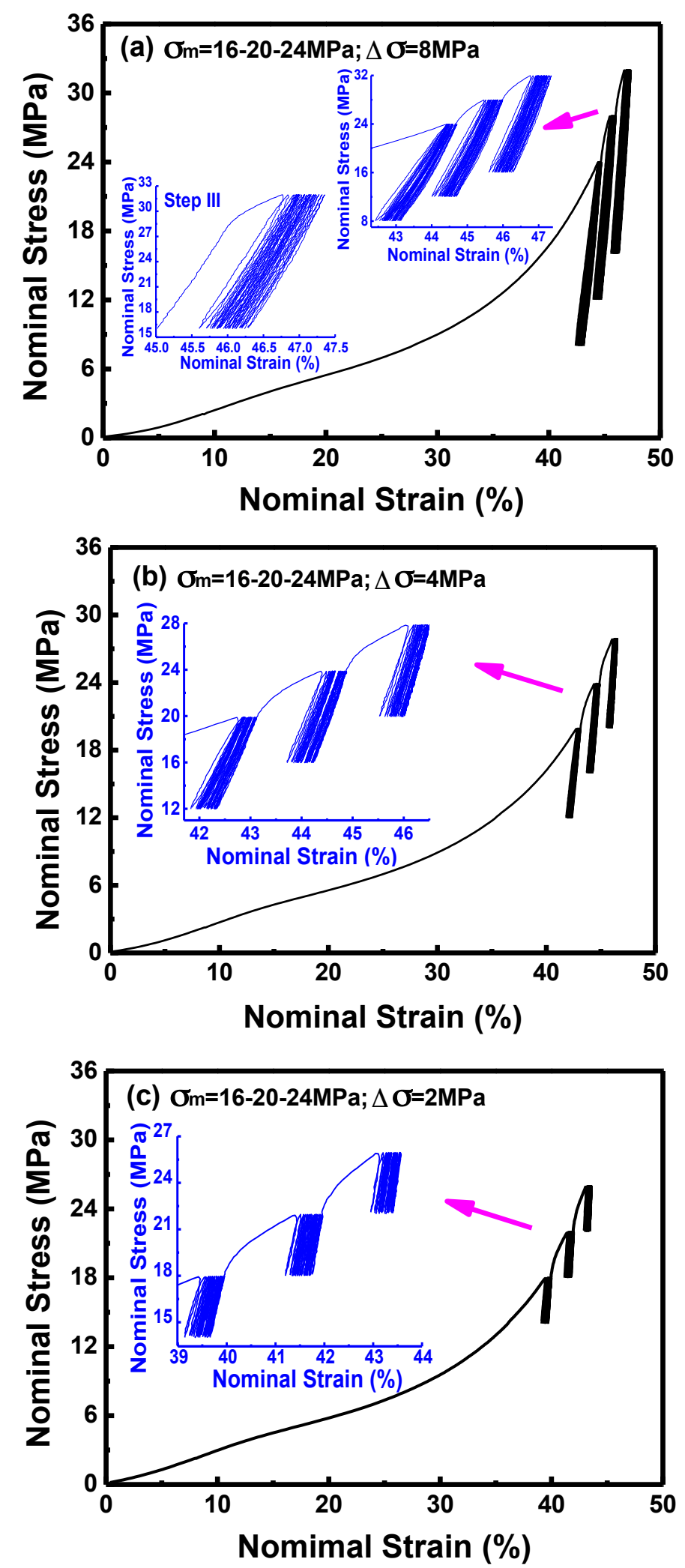

Figure 12. Cyclic compressive nominal stress-strain curves of Type 3865 specimen under three load steps at $500^{\circ} \mathrm{C}$; (a) $\Delta \sigma=8 \mathrm{MPa}$, (b) $\Delta \sigma=4 \mathrm{MPa}$, (c) $\Delta \sigma=2 \mathrm{MPa}$ 

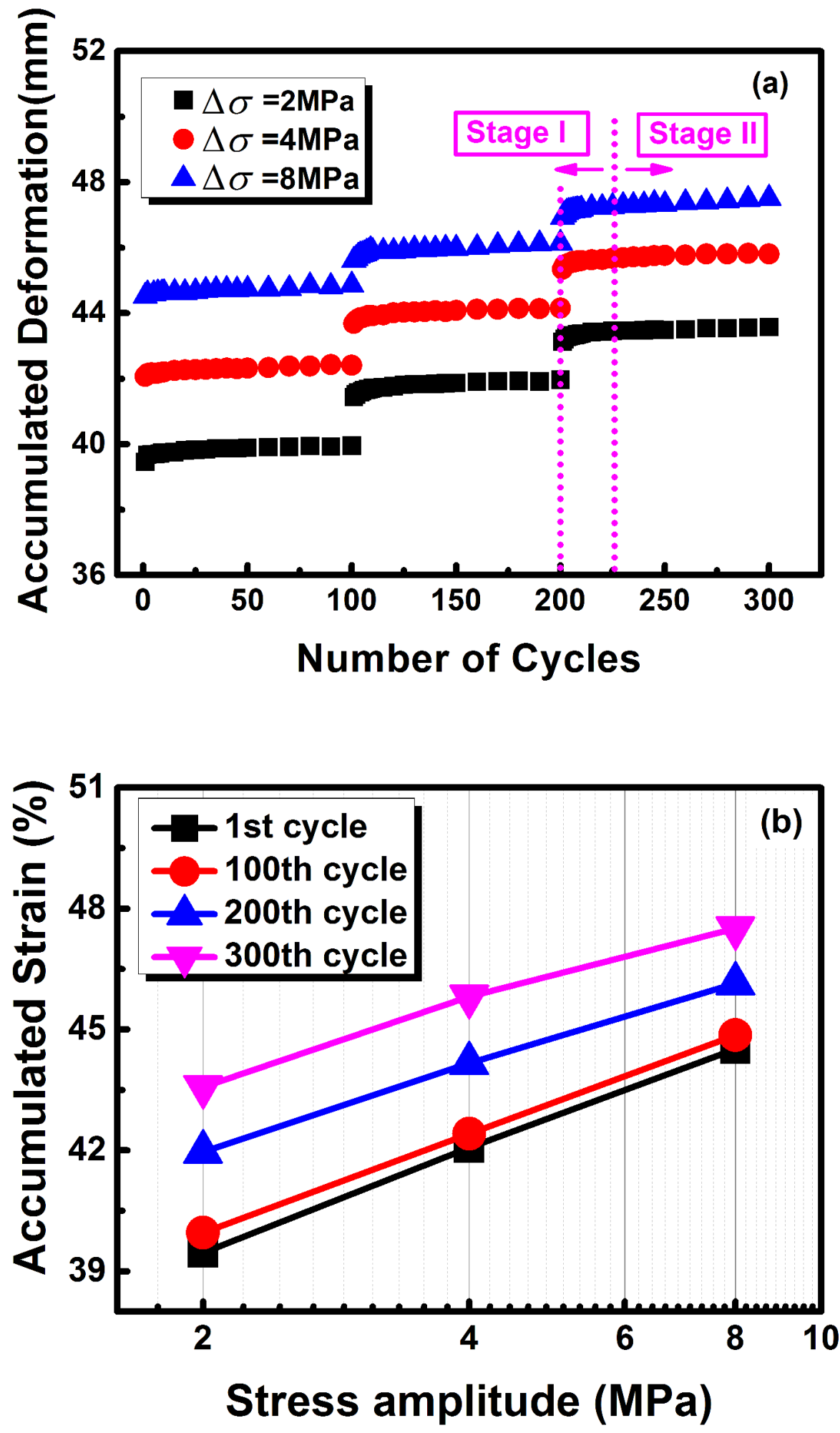

Figure 13. Accumulated compressive strain of Type 3865 specimen under three load steps; (a) accumulated strain versus number of cycles, (b) accumulated strain versus stress amplitude 


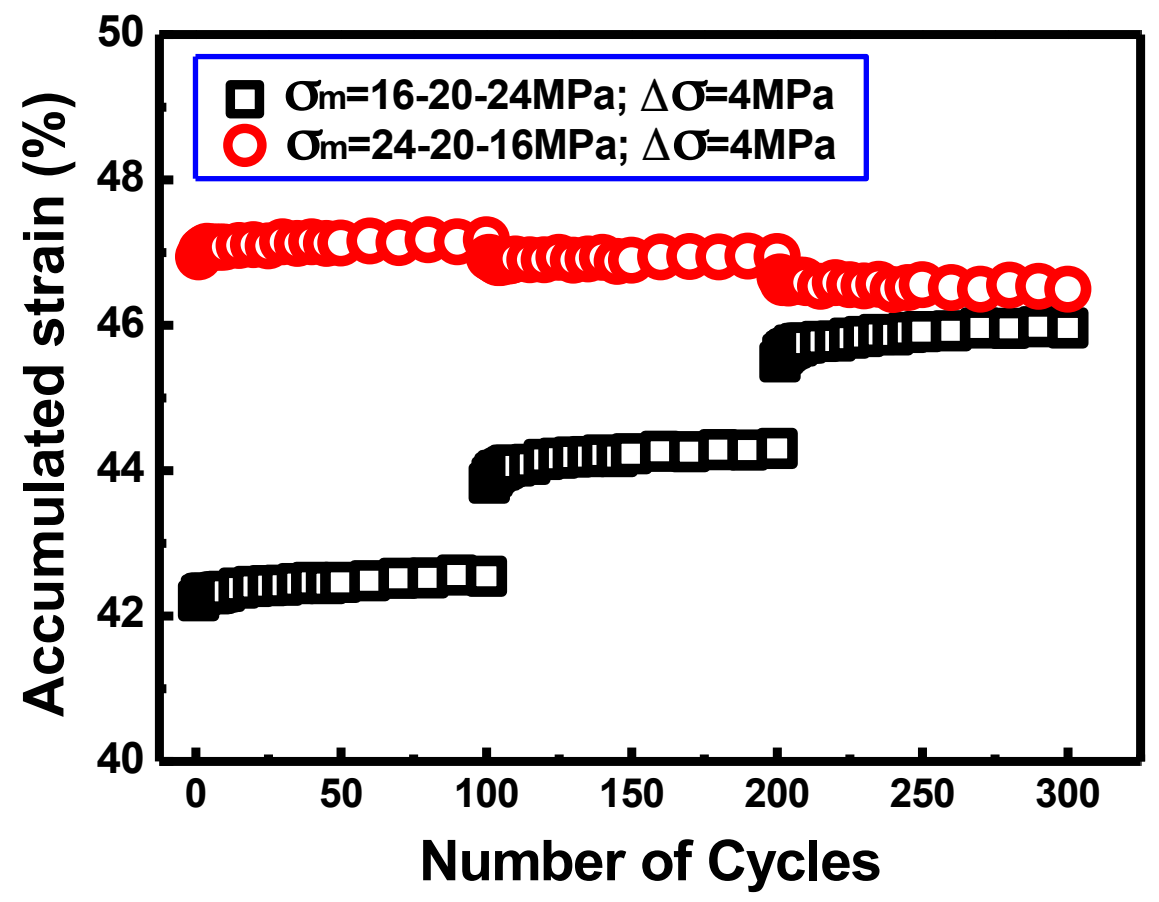

Figure 14. Accumulated compressive strain of Type 3865 specimen under three load steps with different load sequences. 


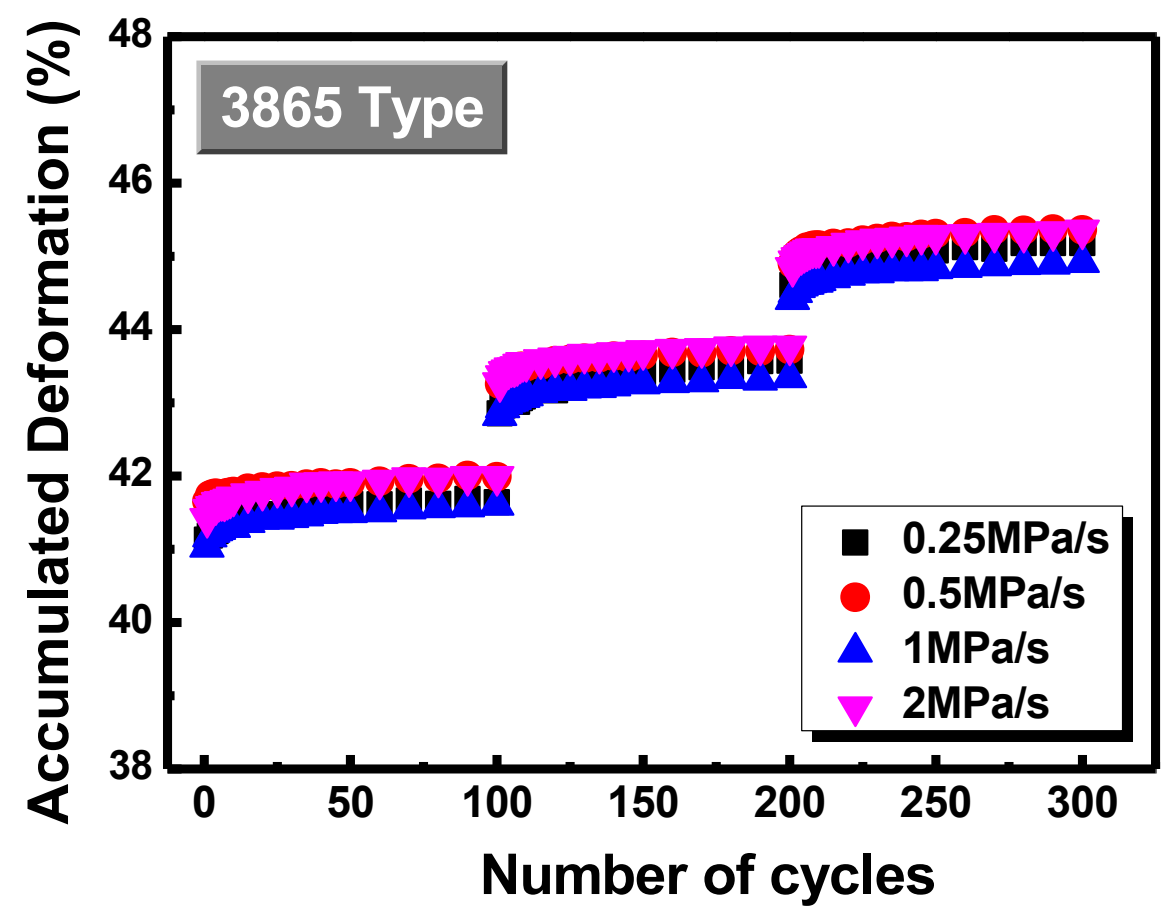

Figure 15. Accumulated compressive strain of Type 3865 specimen under three load steps with different stress rates. 